\title{
In Vitro additive effect on griseofulvin and terbinafine combinations against multidrug-resistant dermatophytes
}

\author{
Aline Jacobi Dalla Lana ${ }^{1}$, Bruna Pippi ${ }^{1}$, Anderson Ramos Carvalho ${ }^{1}$, Renata Cougo Moraes ${ }^{1}$, \\ Samuel Kaiser ${ }^{1}$, George Gonzalez Ortega ${ }^{1}$, Alexandre Meneghello Fuentefria ${ }^{1}$, Gustavo Pozza \\ Silveira*2
}

\author{
${ }^{1}$ Faculdade de Farmácia, Universidade Federal do Rio Grande do Sul, Porto Alegre, Brazil, ${ }^{2}$ Departamento de Química \\ Orgânica, Universidade Federal do Rio Grande do Sul, Porto Alegre, Brazil
}

\begin{abstract}
Griseofulvin (GF) and terbinafine (TF) are commonly used drugs to treat dermatophytosis, a fungal infection of the skin. Today there is an increase in drug resistance to these antifungals which highlight the need for alternative synergistic therapies. Minimum Inhibitory Concentration (MIC) of GF and TF were determined against fungi clinical isolates from local hospitals with values ranging $0.03-2.0 \mu \mathrm{g}$ $\mathrm{mL}^{-1}$ and $0.24-4.0 \mu \mathrm{g} \mathrm{mL}^{-1}$, respectively. A checkboard test was used to determine the combination of GF:TF which could induce an additive effect-against the fungi isolates Multidrug-resistant isolates showed susceptibility after treatment with 16:2 $\mu \mathrm{g} \mathrm{mL} \mathrm{m}^{-1} \mathrm{GF}$ :TF. An MTT assay further verified that GF and TF combinations have greater additive effect against pathological and multidrug-resistant isolates than antifungals alone. Herein we disclose GF:TF combinations that could constitute as a possible new anti-dermatophyte therapy.
\end{abstract}

Keywords: Griseofulvin. Terbinafine. Dermatophyte. Multidrug-resistant fungi. Drug combination.

\section{INTRODUCTION}

Skin infections caused by dermatophytes fungus are common and widespread worldwide. The disease causing fungus result primarily from three genus Epidermophyton, Microsporum, and Trichophyton. These infections are typically limited to the stratum corneum of skin, nails, and scalp, causing tinea-like mycoses and onychomycosis characterized by the symptoms of local irritation, scaling, redness, swelling, and inflammation (Patel, Schwartz, 2011). Although rarely fatal, these fungal diseases are considered difficult to treat, since their therapy is long and frequently recur (Molina de Diego, 2011).

Fungal resistance to conventional antifungals is on the rise which further complicates the treatment (Grover, Arora, Manchanda, 2012). In addition, it is especially difficult to treat immunocompromised patients because of high toxicity associated with many antifungal agents

\footnotetext{
*Correspondence: G. P. Silveira. Departamento de Química Orgânica, Instituto de Química, Universidade Federal do Rio Grande do Sul. Av. Bento Gonçalves, 9500, Agronomia, 91501-970 - Porto Alegre, Brasil. E-mail: gustavo.silveira@iq.ufrgs.br
}

(Vandeputte, Ferrari, Coste, 2012). Griseofulvin (GF) and terbinafine (TF) are among the most commonly used drugs for the treatment of dermatophytosis but often not effective alone (Badali et al., 2015).

The current approach to treat dermatophytosis utilizes a combination of antifungals to overcome fungal resistance, especially in chronic cases (Tamura et al., 2014). This strategy has been successful against other diseases and is particularly attractive to the pharmaceutical industry since approved drugs gain extra lifetime.

GF and TF act on different targets in the fungal cell. GF alters DNA synthesis inhibiting mitosis by interfering with microtubules function (Kathiravan et al., 2012). Whereas, TF inhibits squalene epoxidase leading to ergosterol depletion and squalene accumulation (Campoy et al., 2017; Scorzoni et al., 2017).

Co-administration of drugs of different mechanisms of action can often be synergist through inhibition of complementary targets inside fungal cells (Scorzoni et al., 2017). This strategy has been shown to achieve a wider spectrum of antifungal activity (Mukherjee et al., 2005; Campitielli et al., 2017; Scorzoni et al., 2017). 
Herein, we present a study of the in vitro effects of GF and TF combinations against multidrug-resistant fungi using fungi clinical isolates, which are simultaneously or individually resistant to GF and TF.

\section{MATERIAL AND METHODS}

\section{Microorganisms}

Clinical fungi isolates (ten strains of $T$. mentagrophytes, eleven of T. rubrum, eight of $M$. canis, and twelve of $M$. gypseum) were obtained from the culture collections deposited on the Laboratory of Applied Mycological Research, Universidade Federal do Rio Grande do Sul, Brazil. PCR and direct sequencing, targeting the internal transcribed spacer (ITS) region of rDNA, were used in the identification of T. mentagrophytes isolates employed in this study.

\section{Antifungal solutions}

Stock solutions of GF (Wallace Pharmaceuticals, Mumbai, India) and TF (terbinafine hydrochloride Cristália, São Paulo, Brazil) were prepared by dilution with dimethyl sulfoxide (DMSO; Synth, São Paulo) at $1600 \mu \mathrm{g} \mathrm{mL}^{-1}$ and stored at $-20^{\circ} \mathrm{C}$. For the experiments, antifungal drugs were diluted with RPMI 1640 (Roswell Park Memorial Institute; Gibco) medium supplemented with L-glutamine, without sodium bicarbonate, and buffered at $\mathrm{pH} 7.0$ with MOPS (morpholinepropansulfonic acid; Sigma-Aldrich) buffer $0.165 \mathrm{M}$. After dilution, the maximum final concentration of DMSO was $2 \%$.

\section{Antifungal susceptibility testing}

The minimum inhibitory concentration (MIC) of each antifungal drug was determined by the broth microdilution method using RPMI 1640 medium, according to CLSI protocol M38-A2 (CLSI, 2008). GF and $\mathrm{TF}$ resistance was defined as $\mathrm{MIC} \geq 3 \mu \mathrm{g} \mathrm{mL}^{-1}$ (Galuppi et al., 2010) and MIC $\geq 4 \mu \mathrm{g} \mathrm{mL}{ }^{-1}$ (Mukherjee et al., 2003), respectively, since no breakpoints are available in the CLSI and EUCAST for these drugs. Sterility (without drugs and fungi) and cell viability controls were used respectively and performed in triplicate.

\section{Phenotypic Study of ATP-binding cassette (ABC) efflux pumps}

MICs of GF and TF were determined to the multiresistant isolates in the presence of verapamil $(100 \mu \mathrm{M}$,
RPMI) into the culture medium and compared with the MIC values without the addition of this efflux pump inhibitor (Pinto e Silva et al., 2009). Incubation conditions were the same as those used on antifungal susceptibility tests.

\section{Susceptibility assay of the combined antifungal drugs by the checkerboard method}

Two-dimensional characterization of the GF:TF interaction was performed in quadruplicate by checkerboard technique as previously described by Lewis et al. (2002). Antifungal interactions were evaluated by comparing the fractional inhibitory concentration index (FICI) expressed as the sum of the fractional inhibitory concentrations (FIC), as defined by the following equation:

$\mathrm{FICI}=\mathrm{FIG}_{\mathrm{GF}}+\mathrm{FIG}_{\mathrm{TF}}=\frac{\mathrm{MIC}_{\mathrm{GF}} \text { in combination }}{\mathrm{MIC}_{\mathrm{GF}} \text { teste dalone }}+\frac{\mathrm{MIC}_{\mathrm{TF}} \text { in combination }}{\mathrm{MIC}_{\mathrm{TF}} \text { tested alone }}$

where $\mathrm{MIC}_{\mathrm{GF}}$ and $\mathrm{MIC}_{\mathrm{TF}}$ are the MICs of GF and TF, respectively (Mukherjee et al, 2005). Interactions were defined as synergistic $(\mathrm{FICI} \leq 0.5)$, additive $(0.5<\mathrm{FICI}<$ $1)$, indifferent $(1 \leq \mathrm{FICI}<4)$, or antagonistic $(\mathrm{FICI} \geq 4)$ (Lewis et al., 2002).

\section{Cell injury test of the combined antifungal drugs}

After the Checkerboard time incubation, the hypha damage caused by GF:TF association was assayed by the colorimetric test using 3-(4,5-dimethylthiazol-2yl)-2,5-diphenyltetrazolium bromide (MTT) (SigmaAldrich) (Chiou et al., 2001). The supernatant from each microplate-well was substituted with $160 \mu \mathrm{L}$ of MTT (0.05 $\left.\mathrm{mg} \mathrm{mL}^{-1}-\mathrm{RPMI}\right)$, followed by incubation at 35 ${ }^{\circ} \mathrm{C}$ for $24 \mathrm{~h}$. Next, the supernatant was replaced with $200 \mu 1$ of isopropanol. Then, $100 \mu 1$ from each well was transferred to another 96-well microplate for absorbance (A) readings at 570 and $690 \mathrm{~nm}$ (EnVision 2104 Multilabel Reader, PerkinElmer, USA). The cell damage (CD\%) was calculated by the equation $\mathrm{CD} \%=\left[1-\left(\mathrm{A}_{570 \mathrm{~nm}}-\mathrm{A}_{690 \mathrm{~nm}}\right.\right.$ with drug $) /\left(\mathrm{A}_{570 \mathrm{~nm}}-\mathrm{A}_{690 \mathrm{~nm}}\right.$ without drug $\left.)\right] \times 100$.

\section{Statistical analysis}

The statistical analysis was performed by ANOVA followed by Tukey's test (Minitab 14.0 software, USA). Data expressed as mean \pm SEM (Standard Error of Mean). Differences were considered statistically significant when $\mathrm{p}<0.05$. 


\section{RESULTS}

\section{Antifungal susceptibility test}

MIC and $\mathrm{MIC}_{50}$ values (Table I) showed that all forty-one isolates tested were more susceptible to TF than GF. GF MIC values among susceptible isolates varied from 0.25 to $2 \mu \mathrm{g} \mathrm{mL}^{-1}$. Seven isolates (MCA 36, MCA 40, MGY 58, TME 16, TME 34, TRU 25, and TRU 43) were classified as resistant (MIC $\geq 3 \mu \mathrm{g} \mathrm{mL}^{-1}$ ) to GF. TF MIC results among susceptible isolates varied from 0.03 to $2.0 \mu \mathrm{g} \mathrm{mL}^{-1}$. Two isolates (TME 16 and TME 34) were classified as resistant (MIC $\geq 4 \mu \mathrm{g} \mathrm{mL}^{-1}$ ). Finally, two isolates (TME 16 and TME 34) were identified as multi-resistant to GF and TF. Statistical analysis also demonstrated higher presence of GF-resistant than TFresistant $(\mathrm{p}<0.05)$ dermatophytes.

\section{Antifungal activity of the GF:TF combination}

Seven isolates characterized as resistant to either GF or TF, and sixteen isolates susceptible to both antifungals were selected for this study. The FICI values calculated revealed an additive effect in about $70 \%$ of these selected strains (Table II). Multidrug-resistant isolates TME 16 and TME 34 showed to be more susceptible to GF:TF mixtures (Table II - bold) which was unexpected but an encouraging result.

\section{Cell damage evaluation by the MTT test}

Sixteen isolates, which presented additive effect in the qualitative checkerboard test (Table II) were then selected to have their its interaction substantiated by the quantitative MTT test The MTT test corroborates to the results obtained by the checkerboard assay because the GF and TF mixtures in all cases could inhibit greater amount of cell growth compared to both drugs alone. (Table III). The statistical analysis of cell damage verified that the combinations were significantly $(p<0.05)$ more effective in all isolates tested.

Cell viability was evaluated in the multidrugresistant isolate TME 16 (Figure 1 - A) and the drug sensitive isolate TME 32 (Figure 1 - B) by the MTT assay. It was found that cell damage to TME 16 was decreased by $40 \%$ after treatment with GF (32 and $16 \mu \mathrm{g} \mathrm{mL}^{-1}$ ) and TF $\left(2 \mu \mathrm{g} \mathrm{mL}^{-1}\right)$. In contrast, treatment with the GF:TF mixtures (16:2 and 64:2 $\mu \mathrm{g} \mathrm{mL}^{-1}$, respectively) resulted in much greater cell damage $(>90 \%)$ indicating possible hypha death due to synergy (Figure $1-\mathrm{A}$ ). Similar trend in potency improvement was noted with to isolate TME 32 as cell damage could be enhanced to $80 \%$ or greater after treatment with GF:TF mixtures (Figure $1-\mathrm{B}$ ).

Statistical analysis of the cell damage further validate that the GF:TF combinations were significantly more effective in all isolates tested $(\mathrm{p}<0.05)$.

\section{Phenotypic study of $A B C$ efflux pumps}

Effect of ABC efflux-pumps on potency was checked by using Verapamil (Sigma), a known efflux pump inhibitor. Drug efflux is one of the main mechanisms responsible for decrease the MIC within drug resistant organism. It was found that the MICs of GF and TF were not changed with addition of verapamil suggesting that drug efflux is not responsible for drug resistance.

\section{DISCUSSION}

According to the critical points chosen from Table I, seven out forty-one isolates assayed were classified as resistant to GF (MIC values $\geq 3 \mu \mathrm{g} \mathrm{mL}^{-1}$ ) (Galuppi et al., 2010). This finding is consistent with previously reported results (Galuppi et al., 2010; Nardoni et al., 2013) as was the prevalence of GF-resistant isolates compared to TF (Andes et al., 2006).

Two T. mentagrophytes isolates (TME 16 and TME 32) showed resistance to GF and TF. This resistance to distinct antifungal drug classes is alarming, since the probability of therapeutic-treatment failure could be extremely high when these agents are given alone. The multi-drug resistance of dermatophytes to GF and TF is unusual, so further tests was performed focusing on these two multidrug-resistant isolates.

Literature has reported that one particular fungi strain (having resistance to GF, and tioconazole) which was related to the efflux pumps (Fachin, Maffei, MartinezRossi, 1996). Therefore, we hypothesized that TME 16 and TME 32 might be drug resistant due to the activity of efflux pumps. This was checked using verapamil to inhibit the ABC efflux pumps and MICs determined. Since the MICs were not improved upon addition of verapamil it is suggestive that the mechanism of resistance is not drug efflux. Additional studies will need to be conducted to further verify this result and uncover the mechanism of drug resistance.-

Dermatophytosis is often a chronic, recurrent disease which can require long-term treatment with antifungals. Therefore, it is important to choose the most appropriate and effective drugs in the early stages of infection. Combination therapy of antifungals with different pharmacological effects has shown to have 
TABLE I - MICs to GF and TF against dermatophyte isolates

\begin{tabular}{|c|c|c|c|c|c|c|c|}
\hline \multirow{2}{*}{ Isolates } & & \multicolumn{3}{|c|}{$\mathrm{GF}(\mu \mathrm{g} / \mathrm{mL})$} & \multicolumn{3}{|c|}{$\mathrm{TF}(\mu \mathrm{g} / \mathrm{mL})$} \\
\hline & & MIC & Mean MIC & $\mathrm{MIC}_{50}$ & MIC & Mean MIC & $\mathrm{MIC}_{50}$ \\
\hline \multirow{8}{*}{ Microsporum canis } & MCA 01 & 1.0 & \multirow{8}{*}{8.38} & \multirow{8}{*}{0.5} & 0.03 & \multirow{8}{*}{0.30} & \multirow{8}{*}{0.125} \\
\hline & MCA 29 & 0.5 & & & 0.125 & & \\
\hline & MCA 32 & 0.5 & & & 0.125 & & \\
\hline & MCA 36 & $>32.0$ & & & 1.0 & & \\
\hline & MCA W3 & 0.25 & & & 0.06 & & \\
\hline & MCA 38 & 0.5 & & & 0.03 & & \\
\hline & MCA 39 & 0.25 & & & 0.03 & & \\
\hline & MCA 40 & $>32.0$ & & & 1.0 & & \\
\hline \multirow{12}{*}{ Microsporum gypseum } & MGY 42 & 1.0 & \multirow{12}{*}{3.91} & \multirow{12}{*}{1.0} & 0.03 & \multirow{12}{*}{0.24} & \multirow{12}{*}{0.06} \\
\hline & MGY 45 & 1.0 & & & 0.03 & & \\
\hline & MGY 46 & 1.0 & & & 0.03 & & \\
\hline & MGY 48 & 2.0 & & & 0.125 & & \\
\hline & MGY 49 & 1.0 & & & 0.03 & & \\
\hline & MGY 50 & 2.0 & & & 0.125 & & \\
\hline & MGY 51 & 2.0 & & & 0.25 & & \\
\hline & MGY 52 & 1.0 & & & 0.125 & & \\
\hline & MGY 53 & 2.0 & & & 0.06 & & \\
\hline & MGY 54 & 1.0 & & & 0.06 & & \\
\hline & MGY 57 & 1.0 & & & 0.03 & & \\
\hline & MGY 58 & $>32.0$ & & & 2.0 & & \\
\hline \multirow{10}{*}{ Trichophyton mentagrophytes } & TME 16 & $>32.0$ & \multirow{10}{*}{7.15} & \multirow{10}{*}{0.5} & 4.0 & \multirow{10}{*}{0.84} & \multirow{10}{*}{0.03} \\
\hline & TME 18 & 2.0 & & & 0.06 & & \\
\hline & TME 31 & 0.5 & & & 0.03 & & \\
\hline & TME 32 & 1.0 & & & 0.06 & & \\
\hline & TME 33 & 0.5 & & & 0.03 & & \\
\hline & TME 34 & $>32.0$ & & & 4.0 & & \\
\hline & TME 38 & 2.0 & & & 0.03 & & \\
\hline & TME 40 & 0.5 & & & 0.03 & & \\
\hline & TME 44 & 0.5 & & & 0.03 & & \\
\hline & TME 46 & 0.5 & & & 0.125 & & \\
\hline \multirow{11}{*}{ Trichophyton rubrum } & TRU 20 & 1.0 & \multirow{11}{*}{4.45} & \multirow{11}{*}{1.0} & 0.06 & & \multirow{11}{*}{0.03} \\
\hline & TRU 23 & 1.0 & & & 0.03 & & \\
\hline & TRU 25 & $>32.0$ & & & 1.0 & & \\
\hline & TRU 40 & 1.0 & & & 0.06 & & \\
\hline & TRU 42 & 2.0 & & & 0.03 & & \\
\hline & TRU 43 & 4.0 & & & 0.03 & 0.12 & \\
\hline & TRU 46 & 2.0 & & & 0.03 & & \\
\hline & TRU 48 & 2.0 & & & 0.03 & & \\
\hline & TRU 49 & 1.0 & & & 0.03 & & \\
\hline & TRU 50 & 1.0 & & & 0.06 & & \\
\hline & TRU 52 & 2.0 & & & 0.03 & & \\
\hline
\end{tabular}

Isolates having MIC $\geq 4 \mu \mathrm{g} / \mathrm{ml}$ are classified as resistant to the drugs. Bold: multi-resistant isolates. 
In Vitro additive effect on griseofulvin and terbinafine combinations against multidrug-resistant dermatophytes

TABLE II - Fractional inhibitory concentration index (FICI) and type of interaction obtained for hyphae by testing GF:TF combinations according to the checkerboard microdilution method (qualitative methodology)

\begin{tabular}{|c|c|c|c|c|c|c|}
\hline \multirow{2}{*}{ Isolates } & \multicolumn{2}{|c|}{$\mathrm{MIC}(\mu \mathrm{g} / \mathrm{mL})$} & \multicolumn{2}{|c|}{ MIC Combinations $(\mu \mathrm{g} / \mathrm{mL})$} & \multirow{2}{*}{ FICI } & \multirow{2}{*}{ Interaction } \\
\hline & GF & TF & GF & TF & & \\
\hline MCA 29 & 0.50 & 0.12 & 0.25 & 0.06 & 0.98 & Add \\
\hline MCA 32 & 0.50 & 0.12 & 0.25 & 0.06 & 0.98 & Add \\
\hline MCA 36 & 32.00 & 1.00 & 0.25 & 1.00 & 1.01 & Ind \\
\hline MCA 38 & 0.50 & 0.03 & 0.12 & 0.01 & 0.58 & Add \\
\hline MCA 39 & 0.25 & 0.03 & 0.06 & 0.01 & 0.57 & Add \\
\hline MCA 40 & 32.00 & 1.00 & 0.25 & 1.00 & 1.01 & Ind \\
\hline MGY 46 & 2.00 & 0.03 & 0.50 & 0.01 & 0.58 & Add \\
\hline MGY 48 & 2.00 & 0.12 & 0.12 & 0.06 & 0.54 & Add \\
\hline MGY 50 & 2.00 & 0.12 & 0.50 & 0.06 & 0.73 & Add \\
\hline MGY 53 & 2.00 & 0.06 & 0.50 & 0.03 & 0.75 & Add \\
\hline MGY 58 & 32.00 & 2.00 & 0.25 & 2.00 & 1.01 & Ind \\
\hline TME 16* & 64.00 & 4.00 & 16.00 & 2.00 & 0.75 & Add \\
\hline TME 18 & 2.00 & 0.06 & 1.00 & 0.06 & 0.67 & Add \\
\hline TME 32 & 1.00 & 0.06 & 0.06 & 0.03 & 0.56 & Add \\
\hline TME 33 & 0.50 & 0.03 & 0.03 & 0.03 & 1.06 & Ind \\
\hline TME 34* & 64.00 & 4.00 & 16.00 & 2.00 & 0.75 & Add \\
\hline TRU 20 & 1.00 & 0.06 & 0.125 & 0.03 & 0.63 & Add \\
\hline TRU 25 & 32.00 & 1.00 & 0.25 & 1.00 & 1.01 & Ind \\
\hline TRU 42 & 2.00 & 0.03 & 1.00 & 0.007 & 0.73 & Add \\
\hline TRU 46 & 2.00 & 0.06 & 0.50 & 0.03 & 0.75 & Add \\
\hline TRU 48 & 2.00 & 0.03 & 0.25 & 0.03 & 1.01 & Ind \\
\hline TRU 50 & 1.00 & 0.06 & 0.50 & 0.03 & 1.00 & Ind \\
\hline TRU 52 & 2.00 & 0.06 & 0.25 & 0.03 & 0.63 & Add \\
\hline
\end{tabular}

Synergistic (Syn); additive (Add); indifferent (Ind). *multi-resistant isolates.

TABLE III - Cell damage after treatment with GF, TF, and GF:TF combinations (quantitative methodology)

\begin{tabular}{|c|c|c|c|c|c|c|c|}
\hline \multirow[t]{2}{*}{ Strains } & & \multicolumn{6}{|c|}{$\begin{array}{c}\text { C }(\mu \mathrm{g} / \mathrm{mL}) \mathrm{GF}, \mathrm{TF} \\
\text { CDA }(\%) \text { GF, TF } \\
\text { CDC (\%) GF:TF Combinations }\end{array}$} \\
\hline & & \multicolumn{2}{|c|}{ Comb 1} & \multicolumn{2}{|c|}{ Comb 2} & \multicolumn{2}{|c|}{ Comb 3} \\
\hline \multirow{3}{*}{ MCA 29} & $\mathrm{C}$ & 0.25 & 0.06 & & & & \\
\hline & CDA & $27.9 \%{ }^{\mathrm{C}}$ & $42.7^{\mathrm{B}}$ & & & & \\
\hline & $\mathrm{CDC}$ & \multicolumn{2}{|c|}{$80.9^{A}$} & & & & \\
\hline \multirow{3}{*}{ MCA 32} & $\mathrm{C}$ & 0.25 & 0.06 & & & & \\
\hline & $\mathrm{CDA}$ & $62.6 \%{ }^{\mathrm{B}}$ & $51.2^{\mathrm{C}}$ & & & & \\
\hline & $\mathrm{CDC}$ & \multicolumn{2}{|c|}{$87.3^{\mathrm{A}}$} & & & & \\
\hline \multirow{3}{*}{ MCA 38} & $\mathrm{C}$ & 0.25 & 0.01 & 0.125 & 0.01 & 0.25 & 0.007 \\
\hline & $\mathrm{CDA}$ & $55.3 \%{ }^{\mathrm{B}}$ & $63.1^{\mathrm{B}}$ & $37.2 \%{ }^{\mathrm{C}}$ & $63.1^{\mathrm{B}}$ & $55.3 \%{ }^{\mathrm{B}}$ & $39.3^{c}$ \\
\hline & $\mathrm{CDC}$ & \multicolumn{2}{|c|}{$89.6^{\mathrm{A}}$} & \multicolumn{2}{|c|}{$88.7^{\mathrm{A}}$} & \multicolumn{2}{|c|}{$88.0^{\mathrm{A}}$} \\
\hline
\end{tabular}


TABLE III - Cell damage after treatment with GF, TF, and GF:TF combinations (quantitative methodology) (cont.)

\begin{tabular}{|c|c|c|c|c|c|c|c|}
\hline \multirow[t]{3}{*}{ Strains } & & \multicolumn{6}{|c|}{$\begin{array}{c}\text { C }(\mu \mathrm{g} / \mathrm{mL}) \mathrm{GF}, \mathrm{TF} \\
\text { CDA }(\%) \text { GF, TF } \\
\text { CDC }(\%) \text { GF:TF Combinations }\end{array}$} \\
\hline & & \multicolumn{2}{|c|}{ Comb 1} & \multicolumn{2}{|c|}{ Comb 2} & \multicolumn{2}{|c|}{ Comb 3} \\
\hline & $\mathrm{C}$ & 0.25 & 0.01 & 0.125 & 0.01 & & \\
\hline \multirow[t]{3}{*}{ MCA39 } & $\mathrm{CDA}$ & $36.2 \%{ }^{\mathrm{B}}$ & $37.1^{\mathrm{B}}$ & $35.2 \%{ }^{\mathrm{B}}$ & $37.1^{\mathrm{B}}$ & & \\
\hline & $\mathrm{CDC}$ & \multicolumn{2}{|c|}{$82.6^{\mathrm{A}}$} & \multicolumn{2}{|c|}{$80.5^{\mathrm{A}}$} & & \\
\hline & $\mathrm{C}$ & 1.0 & 0.125 & 0.125 & 0.5 & & \\
\hline \multirow[t]{3}{*}{ MGY 46} & CDA & $20.7 \%$ D & $36.3^{\mathrm{C}}$ & $36.3^{\mathrm{C}}$ & $11.4 \%{ }^{\mathrm{E}}$ & & \\
\hline & $\mathrm{CDC}$ & \multicolumn{2}{|c|}{$87.7^{\mathrm{A}}$} & \multicolumn{2}{|c|}{$80.2^{\mathrm{A}}$} & & \\
\hline & $\mathrm{C}$ & 1.0 & 0.06 & 0.25 & 0.06 & 0.125 & 0.06 \\
\hline \multirow[t]{3}{*}{ MGY 48} & CDA & $64.9 \%{ }^{\text {в }}$ & $70.9^{\text {в }}$ & $21.1 \% \mathrm{D}$ & $70.9^{\text {в }}$ & $29.9 \% \mathrm{CD}$ & $70.9^{\mathrm{B}}$ \\
\hline & $\mathrm{CDC}$ & \multicolumn{2}{|c|}{$91.7^{\mathrm{A}}$} & \multicolumn{2}{|c|}{$90.3^{\mathrm{A}}$} & \multicolumn{2}{|c|}{$88.9^{\mathrm{A}}$} \\
\hline & $\mathrm{C}$ & 0.5 & 0.06 & 0.06 & 0.25 & & \\
\hline \multirow{3}{*}{ MGY 50} & $\mathrm{CDA}$ & $57.9 \%{ }^{\text {в }}$ & $53.2^{\text {в }}$ & $53.2^{\text {в }}$ & $34.8 \%^{\mathrm{C}}$ & & \\
\hline & $\mathrm{CDC}$ & \multicolumn{2}{|c|}{$90.1^{\mathrm{A}}$} & \multicolumn{2}{|c|}{$82.5^{\mathrm{A}}$} & & \\
\hline & $\mathrm{C}$ & 1.0 & 0.03 & 0.5 & 0.03 & & \\
\hline \multirow[t]{3}{*}{ MGY 53} & CDA & $52.8 \%{ }^{\mathrm{C}}$ & $27.0^{\mathrm{D}}$ & $3.9 \% \mathrm{E}$ & $27.0^{\mathrm{D}}$ & & \\
\hline & $\mathrm{CDC}$ & \multicolumn{2}{|c|}{$92.7^{\mathrm{A}}$} & \multicolumn{2}{|c|}{$80.9^{\text {B }}$} & & \\
\hline & $\mathrm{C}$ & 32.0 & 2.0 & 16.0 & 2.0 & & \\
\hline \multirow[t]{3}{*}{ TME 16} & $\mathrm{CDA}$ & $35.1 \%{ }^{\mathrm{A}}$ & $30.9^{\mathrm{B}}$ & $6.8 \%^{\mathrm{A}}$ & $30.9^{\mathrm{B}}$ & & \\
\hline & $\mathrm{CDC}$ & \multicolumn{2}{|c|}{$94.2^{\mathrm{C}}$} & \multicolumn{2}{|c|}{$90.3^{\mathrm{C}}$} & & \\
\hline & $\mathrm{C}$ & 1.0 & 0.06 & 1.0 & 0.03 & & \\
\hline \multirow[t]{3}{*}{ TME 18} & CDA & $67.6 \%{ }^{\mathrm{C}}$ & $63.5^{\mathrm{C}}$ & $67.6 \%{ }^{\mathrm{C}}$ & $41.1^{\mathrm{D}}$ & & \\
\hline & $\mathrm{CDC}$ & & & & & & \\
\hline & $\mathrm{C}$ & 0.25 & 0.03 & 0.125 & 0.03 & 0.06 & 0.03 \\
\hline TME 32 & $\mathrm{CDA}$ & $45.4 \%{ }^{\mathrm{B}}$ & $30.5^{\mathrm{C}}$ & $37.9 \%{ }^{\mathrm{BC}}$ & $30.5^{\mathrm{C}}$ & $31.5 \%{ }^{\mathrm{C}}$ & $30.5^{\mathrm{C}}$ \\
\hline & $\mathrm{CDC}$ & & & & & & \\
\hline & $\mathrm{C}$ & 32.0 & 2.0 & 16.0 & 2.0 & & \\
\hline TME 34 & $\mathrm{CDA}$ & $48.7 \%{ }^{\mathrm{B}}$ & $35.5^{\mathrm{B}}$ & $47.7 \%^{\text {в }}$ & $35.5^{\text {в }}$ & & \\
\hline & $\mathrm{CDC}$ & & & & & & \\
\hline & $\mathrm{C}$ & 0.5 & 0.03 & 0.25 & 0.03 & 0.125 & 0.03 \\
\hline TRU 20 & $\mathrm{CDA}$ & $77.7 \% \mathrm{BC}$ & $67.5^{\mathrm{C}}$ & $23.5 \% \mathrm{D}$ & $67.5^{\mathrm{C}}$ & $3.9 \%{ }^{\mathrm{E}}$ & $67.5^{\mathrm{C}}$ \\
\hline & $\mathrm{CDC}$ & & & & & & \\
\hline & $\mathrm{C}$ & 1.0 & 0.015 & 1.0 & 0.007 & & \\
\hline TRU 42 & $\mathrm{CDA}$ & $55.1 \%{ }^{\mathrm{C}}$ & $52.5^{\mathrm{C}}$ & $55.1 \%{ }^{\mathrm{C}}$ & $21.4^{\mathrm{D}}$ & & \\
\hline & $\mathrm{CDC}$ & & & & & & \\
\hline & $\mathrm{C}$ & 1.0 & 0.03 & 0.5 & 0.03 & & \\
\hline TRU 46 & $\mathrm{CDA}$ & $55.4 \%{ }^{\text {в }}$ & $41.5^{\mathrm{B}}$ & $37.6 \%{ }^{\mathrm{B}}$ & $41.5^{\mathrm{B}}$ & & \\
\hline & $\mathrm{CDC}$ & & & & & & \\
\hline & $\mathrm{C}$ & 1.0 & 0.03 & 0.5 & 0.03 & 0.25 & 0.03 \\
\hline TRU 52 & $\mathrm{CDA}$ & $79.5 \%{ }^{\text {в }}$ & $79.1^{\text {в }}$ & $33.4 \% \mathrm{DE}$ & $79.1^{\text {в }}$ & $26.6 \%{ }^{\mathrm{E}}$ & $79.1^{\mathrm{B}}$ \\
\hline & $\mathrm{CDC}$ & & & & & & \\
\hline
\end{tabular}

Microsporum canis (MCA); Microsporum gypseum (MGY); Trichophyton mentagrophytes (TME); Trichophyton rubrum (TRU). C: concentration to each antifungal.CDA: percentage of cell damage to GF or TF. CDC: percentage of cell damage to GF:TF combinations $\left(\mathrm{C}_{\mathrm{comb}}=[\mathrm{GF}]+[\mathrm{TF}]\right)$. Comb 1-3: concentrations of GF:TF combinations to result in cellular damage over $80 \%$. Bold: indication of synergist effect. Two superscript letters represents significance $p<0.05$ between treatments. One letter relates to no significant difference. 
A

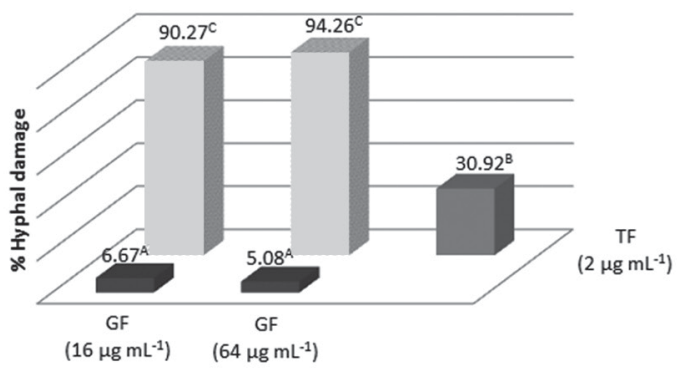

B

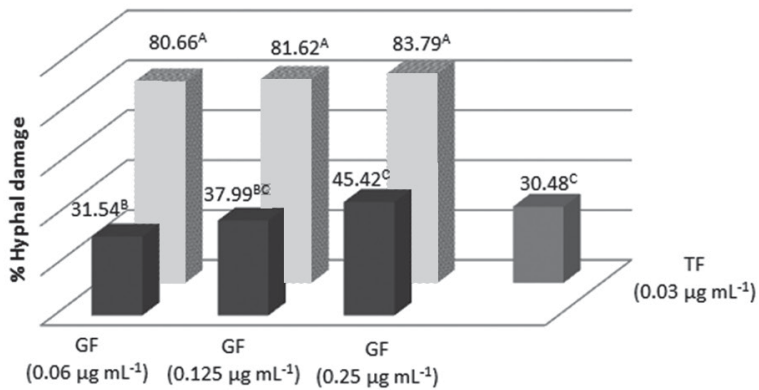

FIGURE 1 - Hyphal damage expressed in percentage of the griseofulvin (GF) ( $\square$ ) and terbinafine (TF) ( $\square$ ) alone and in combination ( $\square$ ). A) Hyphal damage of the TME 16 drug resistant isolate to the combination of TF and GF antifungals at concentrations below MIC; B) Hyphal damage of TME 32 drug sensitive isolate to combination of TF and GF antifungals at concentrations below MIC. Different letters above the hyphal damage represent a statistically significant difference $(p<0.05)$.

merit for treatment of dermatophytosis (Scorzoni et al., 2017).

TF combined with amorolfine was checked in a randomized study of severe dermatophyte onychomycosis. Patients outcome were good and this combination treatment demonstrated an improvement cost per cure ratio (Baran et al., 2000). Onychomycosis caused by dermatophytes were also successfully treated by combination of oral terbinafine with ciclopyroxolamine, imidazole and other such topical antifungals. (Romano et al., 2005). Fusarium oxysporum infections respond positively to TF and topical imidazole treatment and this combination led to clinical and mycological healing, which is often refractory to antimycotics (Romano et al., 2005). Patient recovery to dermatophytosis was also achieved when GF plus cyclopyroxolamine lotion and GF with topical imidazole were chosen and used in combination therapy (Romano et al., 2005). Several other studies of combination therapy were reported, however most of these studies were lacking quantitative data regarding drug combinations in vitro (Spader et al., 2013; Semis et al., 2015).

The qualitative checkerboard assay enabled us to identify combinations of GF and TF which resulted in additive drug effects against sixteen pathogenic fungi (Table II). Subsequent evaluation by the quantitative MTT test using the same sixteen isolates identified by the checkerboard assay was performed and resulted in the determination of GF:TF concentrations that caused over $80 \%$ of cellular damage (Figure 1 ).

Of great importance was discovery of GF:TF drug combination that could cause $90 \%$ and $80 \%$ cellular damage to multidrug-resistant isolates TME 16 and TME 32 , respectively.

It is possible that additive effect was achieved based upon the mechanism of action of GF (nucleic acid inhibitor) and TF (ergosterol synthesis inhibitor). Alteration of the membrane integrity can be linked to squalene epoxidase inhibition by $\mathrm{TF}$, which would promote cellular internalization of GF; while intracellular accumulation would decreases DNA synthesis (Favre, Ryder, 1997; Polak, 1993).

While this is only one biochemical hypothesis, it is also possible that intermolecular bonds in between GF and TB molecules could be responsible for additive effect observed. Our group will be pursuing additional studies to identify these possible interactions and the results will be reported in the due course.

As reported previously we found that GF has low solubility in water (Kahsav et al., 2013). In fact, it was noted that GF partially precipitates in aqueous solution at $35{ }^{\circ} \mathrm{C}$. Consequently, it was necessary to mediate drug precipitation during incubation to avoid misleading results. This was first attempted by using MOPS as a buffer to impart enhanced compound solubility.

However, it is not possible to make the desired stock solutions of GF in concentrations higher than $10 \mu \mathrm{g} \mathrm{mL}^{-1}$ in MOPS buffer at $35^{\circ} \mathrm{C}$ described at the CLSI for MIC determinations (CLSI, 2008). As an alternative, we found that we could make stock solution $1.6 \mathrm{mg} \mathrm{mL}^{-1}$ of GF in DMSO and dilution were made with RPMI 1640 media thereby allowing for proper MICs determinations.

In conclusion, herein we report the first investigation of GF and TF combination drug assessments against a panel of fungi clinical isolates. While, these two drugs have been evaluated with other antifungals (Baran et al., 2000; Romano et al., 2005) our findings are new and noteworthy particularly when pathological dermatophytes have become drug resistant to many antifungal drugs (including GF and TB alone). Through a checkerboard assay, combining GF and TF results in additive effect and has impressive efficacy to several clinical dermatophytes 
including two hard to kill multidrug-resistant fungi isolates. This enhanced activity might be due to having selected drugs of different mechanisms of actions: inhibition of mitosis (GF) and ergosterol depletion (TF), as it is believed that TF might be altering the membrane by blocking the squalene epoxidase which ultimately facilitates cellular internalization of GF allowing for resensitizing via DNA damage of the multidrug-resistant isolates.

\section{ACKONWLEDGMENTS}

This work was supported by Coordenação de Aperfeiçoamento de Pessoal de nível Superior (CAPES). A. M. Fuentefria is grateful to Conselho Nacional de Desenvolvimento Científico e Tecnológico (CNPq) for the PQ fellowships. Authors are thankful to Garrett Moraski and Lowell Markely for their valuable contributions to the final quality of this work.

\section{REFERENCES}

Andes D, Forrest A, Lepak A, Nett J, Marchillo K, Lincoln L. Impact of antimicrobial dosing regimen on evolution of drug resistance in vivo: Fluconazole and Candida albicans. Antimicrob Agents Chemother. 2006;50(7):2374-2383.

Badali H, Mohammadi R, Mashedi O, de Hoog GS, Meis JF. In vitro susceptibility patterns of clinically important Trichophyton and Epidermophyton species against nine antifungal drugs. Mycoses. 2015;58(5):303-307.

Baran R, Feuilhade M, Combernale P, Datry A, Goettmann $\mathrm{S}$, Pietrini $\mathrm{P}$, et al. A randomized trial of amorolfine $5 \%$ solution nail lacquercombined with oral terbinafine compared with terbinafinealone in the treatment of dermatophytic toenailonychomycoses affecting the matrix region. $\mathrm{Br} \mathrm{J}$ Dermatol. 2000;142(6):1177-1183.

Campitelli M, Zeineddine N, Samaha G, Maslak S. Combination antifungal therapy: a review of current data. J Clin Med Res. 2017;9(6):451-456.

Campoy S, Adrio JL. Antifungals. Biochem Pharmacol. 2017;133:86-96.

Chiou CC, Mavrogiorgos N, Tillem E, Hector R, Walsh TJ. Synergy, pharmacodynamics, and time-sequenced ultrastructural changes of the interaction between Nikkomycin $\mathrm{Z}$ and the Echinocandin FK463 against Aspergillus fumigatus. Antimicrob Agents Chemother. 2001;45(12):3310-3321.
Clinical and Laboratory Standards Institute. CLSI. Reference method for broth dilution antifungal susceptibility testing of filamentous fungi; approved standard. 2nd ed. CLSI Document M38-A2. Wayne, PA, USA: Clinical Laboratory Standards Institute; 2008.

Fachin AL, Maffei CML, Martinez-Rossi NM. In vitro susceptibility of Trichophyton rubrum isolates to griseofulvin and tioconazole. Induction and isolation of a resistant mutant to both antimycotic drugs. Mycopathologia. 1996;135(3):141-143.

Favre B, Ryder N. Cloning and expression of squalene epoxidase from the pathogenic yeast Candida albicans. Gene. 1997;189(1):119-126.

Galuppi R, Gambarara A, Bonoli C, Ostanello F, Tampieri MP. Antimycotic effectiveness against dermatophytes: comparison of two in vitro tests. Vet Res Commun. 2010;Suppl 1:S57-61.

Grover C, Arora P, Manchanda V. Comparative evaluation of griseofulvin, terbinafine and fluconazole in the treatment of tinea capitis. Int J Dermatol. 2012;51(4):455-458.

Kahsay G, Adegoke AO, Van Schepdael A, Adams E. Development and validation of a reversed phase liquid chromatographic method for analysis of griseofulvin and impurities. J Pharm Biomed Anal. 2013;80:9-17.

Kathiravan MK, Salake AB, Chothe AS, Dudhe PB, Watode RP, Mukta MS, et al. The biology and chemistry of antifungal agents: A review. Bioorg Med Chem. 2012;20(19):5678-5698.

Lewis RE, Diekema DJ, Messer SA, Pfaller MA, Klepser ME. Comparison of Etest, chequerboard dilution and time-kill studies for the detection of synergy or antagonism between antifungal agents tested against Candida species. J Antimicrob Chemother. 2002;49(2):345-351.

Molina de Diego A. Aspectos clínicos, diagnósticos y terapéuticos de las dermatofitosis Clinical, diagnostic and therapeutic aspects of dermatophytosis. Enferm Infecc Microbiol Clin. 2011;29(Suppl 3):33-39.

Mukherjee PK, Leidich SD, Isham N, Leitner I, Ryder NS, Ghannoum MA. Clinical Trichophyton rubrum strain exhibiting primary resistance to terbinafine. Antimicrob Agents Chemother. 2003;47(1):82-86.

Mukherjee PK, Sheehan DJ, Hitchcock CA, Ghannoum MA. Combination treatment of invasive fungal infections. Clin Microbiol Rev. 2005;18(1):163-194. 
Nardoni S, Mugnaini L, Papini R, Fiaschi M, Mancianti F. Canine and feline dermatophytosis due to Microsporum gypseum: A retrospective study of clinical data and therapy outcome with griseofulvin. J Mycol Med. 2013;23(3):164-1677.

Patel GA, Schwartz RA. Tinea capitis: still an unsolved problem? Mycoses. 2011;54(3):183-188.

Pinto e Silva AT, Costa-de-Oliveira S, Silva-Dias A, Pina-Vaz $\mathrm{C}$, Rodrigues AG. Dynamics of in vitro acquisition of resistance by Candida parapsilosis to different azoles. FEMS Yeast Res. 2009;9(4):626-633.

Polak A. Combination of amorolfine with various antifungal drugs in dermatophytosis. Mycoses. 1993;36(1-2):43-49.

Romano C, Papini M, Ghilar A, Gianni C. Onychomycosis in children: a survey of 46 cases. Mycoses. 2005;48:430-437.

Scorzoni L, Silva ACAP, Marcos CM, Assato PA, de Melo WCMA, de Oliveira HC, et al. Antifungal therapy: new advances in the understanding and treatment of mycosis. Front Microbiol. 2017;8:1-23.
Semis R, Nahmias M, Lev S, Frenkel M, Segal E. Evaluation of antifungal combinations of nystatin-intralipid against Aspergillus terreus using checkerboard and disk diffusion methods. J Mycol Med. 2015;25(1):63-70.

Spader TB, Venturini TP, Rossato L, Denardi LB, Cavalheiro PB, Botton SA, Santurio JM, Alves SH. Synergysm of voriconazole or itraconazole with other antifungal agents against species of Fusarium. Rev Iberoam Micol. 2013;30(3):200-204.

Tamura T, Asahara M, Yamamoto M, Yamaura M, Matsumura $\mathrm{M}$, Goto $\mathrm{K}$, et al. In vitro susceptibility of dermatomycoses agents to six antifungal drugs and evaluation by fractional inhibitory concentration index of combined effects of amorolfine and itraconazole in dermatophytes. Microbiol Immunol. 2014;58(1):1-8.

Vandeputte P, Ferrari S, Coste AT. Antifungal resistance and new strategies to control fungal infections. Int J Microbiol. 2012;2012:713687,1-26.

Received for publication on $19^{\text {th }}$ April 2017 Accepted for publication on $07^{\text {th }}$ November 2017 